\title{
How Health Information Technology Is Failing to Achieve Its Full Potential
}

\author{
Aaron E. Carroll
}

A recent study conducted by the RAND Corporation investigated factors that most influence physician satisfaction. ${ }^{1}$ Many physicians I know expected the findings to include the usual complaints one might see in opinion editorials and press releases from major professional organizations, such as “falling Medicare reimbursement,” "increased regulations,” or “malpractice reform.”

The first main finding that affected professional satisfaction was quality of care. If physicians felt that conditions impaired their ability to provide high-quality care, they were unhappy. The second major cause of dissatisfaction, and perhaps the more significant one, was electronic health records (EHRs). In general, physicians approved of them and liked the idea of checking data remotely. They thought EHRs had the potential to someday improve patient care, but the following litany of complaints against them was long enough to be comical ${ }^{1}$ : They were hard to use. They were time consuming. They interfered with face-to-face communication with patients. They were inefficient. They made work less fulfilling. They could not exchange information with other sources. Many physicians claimed that EHRs even made documentation worse.

These are harsh assessments for something that has often been hailed as the silver bullet for our sometimes-ailing health care system. After all, EHRs are supposed to simultaneously reduce costs, increase efficiency, and improve quality. Unfortunately, such predictions have not played

This is the author's manuscript of the article published in final edited form as:

Carroll, A. E. (2015). How Health Information Technology Is Failing to Achieve Its Full Potential. JAMA Pediatrics, 169(3), 201-202. http://doi.org/10.1001/jamapediatrics.2014.3115 
out as well as many individuals have hoped. Various industries have seen incredible efficiency gains with increased use of information technology. The retail industry has seen an average gain of $1.5 \%$ in productivity with the use of information technology and the telecommunications industry has seen an average gain of $4 \%$; however, studies in medical settings have not consistently seen such results. ${ }^{2}$ A 2006 study $^{3}$ of the effect of improved health information technology (HIT) in medical offices found modest improvements in efficiency through the transition of some office visits to telephone calls, but these were countered by increases in documentation time and a near doubling in the time it took to place orders.

Health information technology should have the potential to improve patient care. The number of pediatricians who are aware of clinical practice guidelines can be shockingly low. Decision support could improve this immensely. Studies have shown that HIT can improve patient compliance as well as appropriate referrals for specialty care ${ }^{4}$ but that potential has often failed to reach its intended audience. Although the United States has for decades been proud of its advanced medical technology, its use of HIT has been woefully lagging. In a 2009 study ${ }^{5}$ by the Commonwealth Fund, the United States placed 10th of 11 countries in the percentage of primary care physicians who used an EHR in practice. Only one-quarter of practices in the United States used EHRs. This was one of the reasons why the Health Information Technology for Economic and Clinical Health (HITECH) Act was passed by Congress in 2009. It was meant to minimize the legal, financial, and technical barriers in implementing EHRs in the United States. At first glance, it appears to have succeeded.

In 2008, between $48 \%$ and $55 \%$ of hospitals adopted either physician-documentation technology or computerized physician-order entry systems. ${ }^{6}$ By 2011 , that number increased to $77 \%$. This 
might seem as though the HITECH Act had an effect but a recent analysis ${ }^{6}$ showed that even without the HITECH Act, it is likely that we would have achieved 67\% adoption by 2011. This means that the government spent about \$48 million for each additionally adopted EHR.

Moreover, it appears that adoption benchmarks improved only by 2 years. ${ }^{6}$ Was this investment worth it? That is debatable given today's status of HIT.

Health information technology has 3 main varieties. At the highest level are health information exchanges (HIEs), which allow for data sharing between clinical environments and public health departments. Theoretically, physicians can access data from multiple hospitals and health care environments. However, research on HIEs shows that although there have been benefits to data access and exchange, as well as some improvements in communication and coordination, access to relevant patient data—-the real selling point of HIEs—-was not achieved. ${ }^{7}$ At the level of hospitals and clinics are EHRs. These are the major focus of the HITECH Act. Electronic health records have shown their ability to perform validations, check for drug interactions, dose drugs appropriately, and store and retrieve data.

Although reports and studies exist that highlight individual successes, most systems are not reaching their full potential. Too few off-the-shelf EHRs have comprehensive decision support that allows patient outcomes to be improved. Too few are easily integrated into registries that could improve disease management. Interoperability issues can impair the transitions of patients from one facility or office to another. Although distance monitoring and personal health data are popular, very few systems are prepared to integrate home data and use it. Finally, although quality metrics are becoming an integral part of reimbursement and reporting, not enough EHRs can track and report on them easily. Patient-centered health records are gaining steam in many 
areas. Data for these records can come from many places, including patients. Advocates believe they can improve long-term care management and lead to improved communication between patients and the health care system.

However, in so many ways, the difference between what we believe HIT can do and what it actually can do is vast. There is a lack of research in underresourced settings, which might see the greatest benefit from HIT. Findings are often not generalizable. Quality improvement methods, which are often needed to adapt HIT to new environments, are lacking. Moreover, HIT is not an unequivocal benefit. It can lead to harms. A 2006 study $^{8}$ showed that computerized physician order entry introduction in a pediatric intensive care unit led to an increase in mortality. Concerns about delays and increased documentation ties along with fragmented displays, inflexible formats, missed renewal notices, and dosage guideline misinterpretations likely led to this undesirable outcome. ${ }^{9}$ Other studies have found different results ${ }^{10}$ but this merely highlights the problem that HIT systems are not all the same and not all universally effective.

Just recently, the American Medical Association called for an overhaul of EHRs, arguing that the meaningful-use requirements set by the government require EHRs to do too many things adequately, making them perhaps unable to do too few things well. The American Medical Association argued for a new framework that would focus on making EHRs more usable and more likely to achieve better patient care. Given what we know about physician satisfaction, this seems aligned with what physicians want: EHRs to be more functional, more user friendly, and less of an impediment to workflow. Physicians also want to see patients receiving high-quality care. It seems possible for HIT to accomplish both of these goals if we focus on the right factors. 


\section{References}

1. Friedberg MW; American Medical Association. Factors Affecting Physician Professional Satisfaction and Their Implications for Patient Care, Health Systems, and Health Policy. Santa Monica, CA: RAND Health; 2013.

2 Kellermann AL, Jones SS. What it will take to achieve the as-yet-unfulfilled promises of health information technology. Health Aff (Millwood). 2013;32(1):63-68.

3 Sidorov J. It ain't necessarily so: the electronic health record and the unlikely prospect of reducing health care costs. Health Aff (Millwood). 2006;25(4):1079-1085.

4 Poon EG, Haas JS, Louise Puopolo A, et al. Communication factors in the follow-up of abnormal mammograms. J Gen Intern Med. 2004;19(4):316-323.

5 Schoen C, Osborn R, Doty MM, Squires D, Peugh J, Applebaum S. A survey of primary care physicians in eleven countries, 2009: perspectives on care, costs, and experiences. Health Aff (Millwood). 2009;28(6):w1171-w1183.

6 Dranove D, Garthwaite C, Li B, Ody C. Investment subsidies and the adoption of electronic medical records in hospitals. In: National Bureau of Economic Research Working Paper Series. 2014. No. 20553. http://www.nber.org/papers/w20553. Accessed December 3, 2014.

7 Mäenpää T, Suominen T, Asikainen P, Maass M, Rostila I. The outcomes of regional healthcare information systems in health care: a review of the research literature. Int J Med Inform. 2009;78(11):757-771.

8 Han YY, Carcillo JA, Venkataraman ST, et al. Unexpected increased mortality after implementation of a commercially sold computerized physician order entry system. Pediatrics. 2005;116(6):1506-1512.

9 Ammenwerth E, Talmon J, Ash JS, et al. Impact of CPOE on mortality rates: contradictory 
findings, important messages. Methods Inf Med. 2006;45(6):586-593.

10 Del Beccaro MA, Jeffries HE, Eisenberg MA, Harry ED. Computerized provider order entry implementation: no association with increased mortality rates in an intensive care unit. Pediatrics. 2006;118(1):290-295. 